\title{
FEAR AND RETROTOPIA - CRITICAL REFLECTIONS ON THE RISE OF DEFENSIVE EMOTIONS IN LIQUID MODERNITY
}

\section{Michael Hviid Jacobsen*}

\begin{abstract}
This article critically addresses the contemporary study of what is called 'defensive emotions' such as fear and nostalgia among a number of social theorists. While it may be true that the collective emotions of fear and nostalgia (here framed by the phrase of 'retrotopia') may indeed be on the rise in Western liberal democracies, it is also important to be wary of taking the literature on the matter as a sign that fear and nostalgia actually permeate all levels of culture and everyday life. The article starts out with some reflections on the sociology of emotions and shows how the early interest in emotions (theoretical and empirical) among a small group of sociologists is today supplemented with the rise of a critical social theory using collective emotions as a lens for conducting a critical analysis of the times. Then the article in turn deals with the contemporary interest within varuious quarters of the social sciences with describing, analysing and diagnosing the rise of what is here called 'defensive emotions' - emotions that express and symbolize a society under attack and emotions that are mostly interpreted as negative signs of the times. This is followed by some reflections on the collective emotions of fear and nostalgia/retrotopia respectively. The article is concluded with a discussion of how we may understand and assess this relatively new interest in defensive emotions.
\end{abstract}

Keywords: Defensive emotions, sociology of emotions, fear, nostalgia, retrotopia

\footnotetext{
* Michael Hviid Jacobsen, Professor of Sociology, Aalborg University, Denmark e-mail: mhj@socsci.aau.dk | ORCID: https://orcid.org/0000-0003-0237-1318
} 


\section{Introduction}

We live in emotional times. Obviously, all historical times are to some extent emotional, because they embody, express, circumscribe and provide the historical, social and cultural backdrop for the emotions of the people who happen to live through them. However, our times are perhaps particularly prone to emotional orientation, build-up and outburst, not least due to the accessibility and availability of means to display, communicate, share and manipulate emotional responses (through mass communication, social media, mobile phone technology etc.). In this way, there is now a possibility for emotional expressions and responses to proliferate and be mobilised almost instantaneously and on a global scale.

We also seem to live through emotional times, or perhaps rather a time of emotions, because - many social analysts would agree - welive in times of trouble and perhaps even in a state of perpetual or permanent crisis (see, e.g., Bauman \& Bordoni 2014; Serres 2013). Since the millennium, we have experienced one major crisis of global proportions after the other: the crisis of the international terror threat since 9/11 2001 that transformed the way we travel, the way we relate and the way we live our lives; the financial crisis in 2007 that changed the way we think about the financial sector, economic security and future investments; the immigration crisis that changed the way we think about other cultures, ethnic minorities and national borders; the climatechange crisis that suddenly confronted us with the knowledge of the possible extinction of species and the imminent destruction of the planet; and most recently the corona crisis that has challenged our healthcare systems around the world causing millions of casualties due to the Covid-19 virus. Living under the threat of such seemingly permanent crisis makes emotions - as collective reactions and responses - so much more important to acknowledge and to understand. 
We thus also live in emotional times when it comes to academic interest. Not so many decades ago, emotions were not a widespread or common concern among social scientists, whose 'models of man' (as they are called) would privilege rational or at least non-emotional behaviour. Nowadays, things are different. Emotions are increasingly made the object of social science scrutiny and are regarded as important analytical units for explaining and understanding events and processes in the realms of everyday life and culture (see, e.g., Emotions, Everyday Life and Sociology 2019; Emotions in Culture and Everyday Life 2022).

For example, throughout the past decades 'the sociology of emotions' has experienced something of a rise to prominence within sociological research and increasingly also within sociological theory. This sociological sub-discipline has since the late 1970s spawned significant theoretical and empirical development. As compared to just a few decades ago, today it has thus become much more commonplace - even among major social theorists - to analyse social conditions and social changes through the lens of emotions. It seems as if emotions have now acquired an analytical potential that was unimaginable to many sociologists writing throughout most parts of the preceding century. In addition, within the social sciences we have also witnessed the rise of an emotional-normative stance towards current social events and processes particularly evident, for example, in different varieties of critical social theory, social justice theory, gender studies, queer studies, ecological studies, etc. This emotional-normative engagement with current social issues also challenges the way we understand social science enterprise, its potentials and its problems.

In this exploratory research essay, the author first reflects on the rise of emotions in sociology in general, and secondly explores and critically discusses how particularly the emotions of fear and retrotopia/nostalgia in recent years have become important 'master emotions' through 
which to understand many of the events unfolding in contemporary liquid-modern life and many of the problems confronting liquid-modern society at large. In this way, there is - at least at the level of social theory and social analysis - an unmistakable tendency to focus on emotional states, responses and experiences that have a certain negative or gloomy ring to them, as it were, whereas positive emotional states, responses and experiences seem to be a much less prevalent concern among social researchers. Living through the past two decades and their fair share of crises has seemingly exacerbated this tendency. The essay thus wants to explore and critically discuss how and why in recent decades, and particularly in the slipstream of the emergence of 'the sociology of emotions', so-called 'defensive emotions' (used here in a non-psychological manner) such as fear and retrotopia/nostalgia have become increasingly important prisms for social analysis, diagnosis and critique.

From 'the sociology of emotions' to a critical social theory of emotions

Emotions are part and parcel of every known human society as they inform the thoughts, actions and interactions of people. Emotions are however often unacknowledged - important building-blocks of social organization, at the basis of our everyday lives and inform the motivations, dreams and aspirations of all human beings. Emotions are at the background of actions as well as in the foreground. They are, as it were, at the very heart of social life. Despite their presumed omnipresence, it took sociology quite some time to recognize the importance of emotions in the study of society and to begin to develop concepts, theories and methods to support the study of emotions.

By now, there are many different theories and studies of emotions. Similarly, there are many different schools of thought and research perspectives when trying to grasp the emotionality of individual and social 
life. Theoretically, 'emotions' may be defined, understood and approached in a number of different ways (sometimes thus separating them from their 'sibling experiences' called 'feelings', 'affects', 'sentiments', etc.). Whereas some perspectives prioritize a view of emotions as 'states' (often focusing on physiological/bodily or psychological dimensions of the individuals experiences and relying on an understanding of emotional expressions and experiences as universal), other theories look at emotions as expressions of 'relations' (that emotions are triggered, shaped, managed and sanctioned in different types of relationships), and yet others regard emotions as 'cultures' (for example seeing emotions as historical, social and cultural constructions - thus challenging static or universal understandings). In this research essay, it is predominantly the latter two perspectives that provide the theoretical foundation for the presentation and discussion.

Looking through the work of most sociologists writing during the first two-thirds of the $20^{\text {th }}$ century, however, theinterest in and analyses of emotions were few and far between. The study of emotions was not regarded as a legitimate or opportune preoccupation among sociologists, a topic perhaps belonging more naturally to the discipline of psychology with its interest in the 'inner workings' of the individual. Moreover, whenever the classic sociologists took an interest in emotions and in fact some of them did do so - they often studied emotions merely as epiphenomena used to shed light on other and more important social issues such as social order, the economy or culture. Emotions were therefore not studied in their own right. However, the coming of the socalled 'expressive revolution' (Martin 1981) from the late-1960s onwards meant that emotions and emotional expressivity not only became increasingly accepted in society at large but it also spawned an interest in the study of emotions in sociology and related disciplines devoted to the study of 'society'. 
The development of 'the sociology of emotions' over the past almost half a century has thus been instrumental in promoting research into the multifarious emotional aspects of social and cultural life- and it has pushed or pulled other scholars into the realm of emotions research. Ever since its emergence, the 'sociology of emotions' - or perhaps rather its individual representatives and exponents - have in numerous studies shown the importance of emotions as driving forces behind individual behaviour and collectiveaction, as a silent or more pronounced presence in many everyday life settings, as components in decisionmaking, life-planning and existential considerations, etc. Since emotions are thus an integral part of human relationships, interactions and everyday life, they also in inextricable ways permeate politics, culture and social structure.

Previously, such endeavours would within the confines of sociology and related disciplines mostly have been approached through models of functional explanation, rational decision-making or by behaviourists' experimental studies of rats and pigeons in controlled laboratory environments - or, at best, relegating emotions to the obscure and inexplicable residual Weberian category of 'affectual action'.

However, with the pioneering work of the likes of Arlie R. Hochschild, Theodore D. Kemper, Thomas J. Scheff, Candace Clark, Lynn Smith-Lovin, David R. Heise, Randall Collins and many others starting to take the emotional domain seriously throughout the final quarter of the $20^{\text {th }}$ century, emotions began to inspire scholars and students around the world to pay dueattention to the emotionality of social and cultural life at the micro, meso and macro levels (see, e.g. Research Agendas in the Sociology of Emotions 1990). "The sociology of emotions' has aptly been characterized as a special 'way of seeing' and of understanding the world (Hochschild 1998) that, one might say, looks at the intricate interplay between people's emotional experiences and expressions on the one hand and the changes in social structures and 
social formations on the other. This perspective is evident, for example, in books such as The Managed Heart (Hochschild 1983), Misery and Company (Clark 1997) and Interaction Ritual Chains (Collins 2004) that all have provided food for thought - empirical, conceptual and theoretical - in the analysis of emotions as key facets of social life, generically as well as within specific areas of society.

The main reason why emotions were previously almost routinely neglected or surrounded by suspicion within the academic world was well captured by Arlie R. Hochschild when in the mid-1970s she commented:

"Perhaps the main reason sociologists have neglected feeling is that, as sociologists, we are members of the same society as the actors we study, and we share their feelings and values. Our society defines being cognitive, intellectual, or rational dimensions of experience as superior to being emotional or sentimental ... Another reason for sociologists' neglect of emotions may be the discipline's attempt to be recognized as a 'real science' and the consequent need to focus on the most objective and measurable features of social life" (Hochschild 1975: 281).

For these - and undoubtedly many other - reasons, emotions were for a long time regarded as a no-go area for anyone interested in studying society and who wanted to live up to 'scientific standards' of the time (non-normativity, non-emotionality, non-engagement, etc.). There is no doubt that the showdown with what has been called the orthodox consensus' in sociology (Giddens 1979) - with its privileging of, for example, functionalism, behaviourism, positivism and analytical philosophy - paved the way for the rise of 'the sociology of emotions' on the North American continent. With this emergence of 'the sociology of emotions', despite differences in the theoretical preferences of its individual contributors, the days of the total dominance of functional 
or rational explanations were over and emotionality gradually became a niche for those interested in the study of emotions.

Since the early days as a sort of niche or emerging perspective, the sociology of emotions' has throughout the past four decades grown into a considerable sub-field for ground-breaking research into many different areas of emotional life (Bericat 2016). Numerous books are published every year devoted to the study and analysis of emotions, emotion-specific academic journals have now been established, and seminars and conferences on the topic are held on a regular basis. Alongside this development, several high-profile international social theorists Norbert Elias, Anthony Giddens, Ulrich Beck, Zygmunt Bauman, etc. specifically began to incorporate an emotional dimension into their more general sociological frameworks.

Moreover, in recent decades - and often by scholars and theorists not specifically associated with 'the sociology of emotions' - a number of studies have been published that critically look at the overall societal or cultural developments that shape individual and collective emotions, studies concerned, for example, with postemotionalism (Meštrović 1997) or with a number of negative emotional experiences such as anxiety, depression, fear, stress, loneliness, despair, hate, etc. Some of these studies have focused specifically on what might be called 'defensive emotions' - emotions that are somehow regarded as characteristic responses to the pressures and problems of contemporary liquid-modern society.

The rise of 'defensive emotions'

In recent years, there has thus been a noticeable interest within sociology and social theory in writing about some of the main prevailing emotional moods in contemporary society as a sort of prism through which to critically dissect and analyse social development. As mentioned 
above, specifically within 'the sociology of emotions' but increasingly also within the perspective of critical social theory, emotions have in recent decades acquired a momentum as analytical focus points for studying, understanding and critically discussing wider social issues.

There has been a quite significant tendency - within 'the sociology of emotions' as well as within certain variants of critical social theory to use changes in emotions or what Norbert Elias once called 'emotional styles' as a magnifying glass for zooming in on some of the problems and pressures created by contemporary capitalism, the ideology of romanticism, globalization, individualization, consumerism, neoliberalism, etc. In these processes, emotions (sometimes specifically referred to as 'genuine emotions') have been squeezed to the side or replaced by 'artificial emotions' or are being thoroughly commercialized, commodified, manipulated, corrupted or in other ways distorted by the forces of the aforementioned tendencies. The outcome has been experiences of emotional distress, emotional fatigue, alienation, emotional numbing, apathy or downright indifference. In general, most emotions - even socalled 'positive emotions' such as love, trust, loyalty, happiness or compassion - have in different ways and to different degrees thus been exploited or emptied of meaning. It seems as if the distorted emotionality or even unemotionality of contemporary social life has now become an expanding area of concern within critical social theory (see, e.g., Ahmed 2004).

The world has probably always been a scary place to live with many unpleasant sources of fear, misery and human suffering. There is, however, good reason to suspect that humans have been able to live increasingly secure and safe lives (not least due to scientific progress and technological advances), but also that some sources of fear and suffering seem to persist or even be on the rise. In his Civilization and Its Discontents (1930/2002), Sigmund Freud famously posited three main sources of human suffering. First, the relentless rage of the outside 
world in the shape of natural disasters and extreme weather conditions. Second, the steady decline and decay of the potentially sick and dying body - the fact that one of the greatest threats to continued human survival is the all-too-mortal human body. Finally, our relationships to other people as a source of pain and suffering - e.g. harm, wrongdoing, crime, violence, terrorism, etc. It is safe to say that the relative weight of these three sources of suffering in human life is not stable.

It seems as if we have been able to reduce the risks and deal with some of the negative consequences of the former two sources of fear (e.g. through weather forecasting systems, technological inventions and medical advances), whereas the latter form - the relationships to other people- even in peaceful and civilized times is still fraught with dangers (e.g. sexual assault, terrorism, street violence). Even though human average life expectancy has continuously been extended (for example from close to 45 years in 1900 to nowadays around 80 in the Western world, see Roser, Ortiz-Ospina, Ritchie, 2019), weare still facing threats to our health, well-being, security and survival. It is thus particularly the suffering associate with Freud's third category - the relationship to other people - that seems to concern many of those writing about the 'defensive emotions' to which we return below.

When the universal sun starts to set, the moth seeks out the warmth of the domestic lamp. So wrote a young Karl Marx back in the early $19^{\text {th }}$ century (Marx quoted in Bauman 1997: 79). As an allegory of how the perceived threats of rapid social change make people retreat from the collective concerns of the outside world - increasingly regarded as uncertain, insecure and hostile - in order to seek the comforts and cosiness of the close and well-known surroundings, this is perhaps a fitting description of contemporary liquid-modern society. This situation has not escaped the attention of sociologists and certain critical social theorists. As mentioned already, many sociology books - some of which we return to below - have been published in recent decades specifically 
looking at the gloomy emotional atmosphere that has descended upon contemporary society.

True, sociology is generally known often to provide a - perhaps excessively - critical perspective on society and social development, but there is now a certain consensus that the overall 'mood of the world' (Bude 2018) has changed for the worse. In times of optimism, the mood of the world is generally positive, generating collective emotions of social engagement and even collective euphoria. In times of trouble and crisis, however, pessimism prevails and the emotions that seem to define and permeate society are much more negative and defensive, being concerned with trying to ward off the perceived threats and dangers (Bailey 1988).

Many of the emotions prevalent in contemporary liquid-modern society - at least as they are detected and described by critical social theorists - seem to be responses to such times of crisis and trouble: defensive and 'negative' emotions such as stress, depression, fear, anger, rage, anxiety, apathy, injustice, humiliation, hate, etc. In this way, the emotional container is currently full of dark premonitions and magnified worries. Moreover, many of the emotions and emotional states that according to critical sociological analyses nowadays seem to invade private minds and public agendas alike are often manipulated by powerful 'emotional entrepreneurs' we might call them - recalling the 'moral entrepreneurs' that Howard S. Becker (1963) once spoke of - such as the media and politicians. Fear mongering but also nostalgia generation, as we shall see later, seem to be some of the most important strategies pursued in order to gain and maintain political support (perhaps they always were).

Some of these defensive and 'negative' emotions that seem particularly to have attracted the analytical attention of social theorists working with a critical social diagnostic perspective are exactly fear and nostalgia (or retrotopia). Obviously, fear and nostalgia have been around 
for a long time (for example, the first treatise on nostalgia was published as far back as in 1688, see Hofer 1688/1934), but it seems as if these emotions particularly in the new millennium have been regarded as marked signs of the times. Both emotions - fear and nostalgia - can be regarded as offensive and activating emotions (e.g. fear is a much needed flee-or-fight reaction to immediate danger, and nostalgia is a positive and comforting for many when experiencing so-called 'Proustian moments' or entertaining fond memories of one's past). However, within most sections of critical social theory, these emotional responses have largely if not exclusively been linked with much more defensive, negative and problematic social developments. One might even suggest that they express a 'new negative' within sociological theorizing.

The culture of fear

In the early 1930s, at the depths of the despair of the 'Great Depression', American president Franklin D. Roosevelt in his first inaugural speech famously declared that 'the only thing we have to fear is fear itself' (United States Senate 1933). It was a statement directed at those who felt weary by the economic recession and who had lost hope in the future. Obviously, fear has been there all along - it is according to Charles Darwin (1872/ 1999) and others writing from a biological perspective a 'basic human emotion' - but it seems as if this emotion has become particularly useful as a signified of our contemporary cultural and social malaise.

Today, it appears that fear is actually something to fear. A torrent of literature has in recent decades thus testified to the rise of a so-called 'culture of fear' as a phenomenon in many parts of the Western world a situation in many respects exacerbated by the current Covid-19 crisis. However, even well before the arrival of the current Covid-19 scare, the world was perceived as a dangerous place. Throughout thelatter part of 
the 1990s, several critical sociologists pointed to what they called a 'culture of fear'. This culture of fear, it has been observed, was fuelled simultaneously by pre-millennial tensions and fin de siècle uncertainties as well as being promoted by powerful agencies such as politicians and the media. The new millennium quickly produces many new fear-provoking scenarios: 9/ 11-inspired international terrorism, the financial crisis, the ecological crisis, and most recently the Covid-19 global healthcare crisis. Nowadays there seems to be plenty of things to be afraid of.

Thus, a number of critical sociologists and social theorists have dealt with fear as a sort of 'master emotion' in contemporary society - an emotion that embodies and, almost like a prism, reflects many of the deeper challenges confronted by liquid-modern society. Starting out by laying the groundwork for what may be called 'the culture of fear thesis' in the late 1990s, Frank Furedi (1997) and Barry Glassner (1999) each in their way pointed to how fear had become such a powerful presence in society and politics alike that people were increasingly unable to distinguish between actual and imagined/manipulated sources of fear.

Prior to their work, Brian Massumi (1993) had written about the 'politics of everyday fear' and discussed how the roots of the current culture of fear were deep, perhaps even reaching as far back as to the collective emotional response to the assassination of J ohn F. Kennedy in 1963. In the new millennium, several journalists and scholars began theorizing the collective feelings of fear and anxiety as something to be reckoned with in sociological analysis resulting in a growing amount of literature (see, e.g., Bader et al. 2020; Bourke 2005; Bauman 2006; Bude 2014; Entertaining Fear: Rhetoric and the Political Economy of Control 2010; Furedi 2018; Gardner 2008; idem 2009; Koczanowicz 2020; Robin 2004; Schultz 1998; Siegel 2006; Skoll 2010; idem 2016; Wilkinson 2000; Tudor 2003).

From each their perspective, with each their vocabulary, but with what seems to be almost a common agenda, these scholars have written 
substantially on the topic of fear - its causes, processes and dynamics as well as its consequences - and have thus shown how fear seems somehow to be both growing in scale and deepening in its impact in contemporary society. Several of these writers have concerned themselves particularly with how the political realm has served as a prime mover in instrumentally using fear as a strategy to secure votes and political backing. The rise of 'the politics of fear' thus goes hand in hand with 'the culture of fear', which has led to an 'infantilization' of the public (Furedi 2005) as well as to varying degrees of respectively political mobilization on the one hand and political disillusionment and apathy on the other.

According to some contemporary critical social theories, a spectre is thus haunting the world - the spectre of Unsicherheit. This is a notion capturing the combined collective feelings of insecurity, uncertainty and unsafety (Bauman 1999). Zygmunt Bauman is one of the key critical social thinkers who throughout the past decades have taken a keen interest in deciphering a multitude of emotional experiences of and responses to contemporary liquid-modern society such as fear and nostalgia/ retrotopia (J acobsen 2020b). According to Bauman, unlike individual or isolated experiences of fear (e.g. provoked by standing in front of a blood-thirsty tiger), the contemporary feelings of fear are much less object-directed. As he once stated about this new morphology of what he later came to describe as liquid fear':

"We are frightened and confused: confused because frightened and frightened because confused J ust below the ground we walk upon, there seems to be a thick seam of boiling fears which burst, with growing frequency, through the thin crust of daily routine to smother or incinerate everything within vicinity. There is no telling where and when the next eruption will occur. So there are good reasons to be afraid" (Bauman 1996: 21). 
Mostly, the prime movers behind this seemingly unstoppable spectre of 'iquid fear' or Unsicherheit are hidden from plain sight such as the relentless (but nevertheless mostly invisible) processes of globalization, individualization, deregulation and privatisation. Sometimes this fear is personified through the figures of 'the stranger', the terrorist' or 'the immigrant', but most often we are unable to explicate exactly why we feel anxious and fearful. In such a world, being afraid' or 'feeling at risk', as Ulrich Beck (1992) once suggested in his thesis on the risk society, is for many people fast overtaking the experience of being hungry'. (It needs to be noted that although some of the literature on 'the culture of fear' is indeed inspired by Beck's 'risk society' thesis and sometimes reaches some of the same conclusions, the semantic field of these two critical diagnoses of the times - 'culture of fear' and 'risk society' - is not necessarily the same).

In many respects, the current 'culture of fear' seems to be working in a similar fashion to what within sociology been previously been called 'moral panics' that refers to situations when the community - local, national or international - feels (often irrationally) that its values, interests and/ or security is threatened by certain groups or incidents that break with the norms/normality of society (Cohen 1972). Common to many 'moral panics' cycles - as is also a feature of 'the culture of fear' theories' depictions of episodal eruptions of fear - is the fact that the danger is often irrationally perceived, that the social/societal response is often disproportional to the actual risk of the perceived threat, that the 'moral panics' cycles are normally relatively short-lived, and that they fertilize the soil for collective feelings of distrust, stigmatization and the creation of social cleavages and chasms (Thompson 1998; Goode \& Ben-Yehuda 1994).

Nowadays, it seems as if fear (its promotion, its perpetuation and its individual and social consequences) has become a new important prism 
through which to diagnose and understand significant changes and policies in contemporary liquid-modern society. Whereas the real roots of fear are liquid or even remain unknown, the reactions to it are solid and swift - e.g. to impose new restrictions on freedoms, to secure law and order and to promise to punish those who are regarded or labelled as the culprits (Bauman 2006).

In many ways, it seems as if the idea of 'the culture of fear' has now overtaken not only the role previously played by theories of "moral panics', but also the role of the theories of 'the risk society' from the late 1980s and onwards, however mostly completely devoid of the potentially positive aspects associated with risk or risk-taking found, for example, in the writings of Anthony Giddens (1990), Edgework - The Sociology of Risk-Taking (2004) or more recently Paul Slovic (2010) and following mostly the gloomy lead from the writings of Ulrich Beck (1992). Fear, it seems from the vast majority of the writings dealing with 'the culture of fear', is therefore presented almost as a purely defensive and negative emotion threatening to tear societies apart.

Retrotopian times

Besides taking a keen interest in the emotional experience of collective fear, in recent years also the theme of nostalgia has gained a foothold as a fruitful topic of social scientific scrutiny. Perhaps this situation in which nostalgia is now taken seriously in contemporary social research in many ways mirrors the spreading of the emotion in society at large even though this is indeed hard to determine and measure with any accuracy. After being almost entirely absent from the sociological research agenda, 'nostalgia studies' now thrive and provides insights into an emotion that is increasingly mentioned in order to explain and analyse some current social, cultural and political developments. Nowadays, there is a 'politics of nostalgia', a 'nostalgic marketing', a 'media- 
based/ mediated nostalgia', a 'nostalgic consumption' and many other more or less specific or generalized - expressions of the emotion. As mentioned, for many years, the topic of nostalgia did not occupy the minds of many sociologists and social thinkers - the 'nostalgia community' was for a long time small and exclusive.

For many years, the two main sources of reference in most studies have remained Fred Davis' classic Yearning for Yesterday: A Sociology of Nostalgia (1979) and political scientist Svetlana Boym's The Future of Nostalgia (2001). Both books contain an inventory of useful concepts with which to approach and analyse a variety of different types and expressions of nostalgia. In recent years, a new torrent of literature on nostalgia has swept across the social sciences and humanities, testifying to the increased awareness of, interest in and popularity of the topic theoretically as well as empirically (see, e.g., Nostalgia Now - CrossDisciplinary Perspectives on the Past in the Present 2020); Intimations of Nostalgia: Multidisciplinary Explorations of an Enduring Emotion 2021).

This development has also inspired some critical social theorists to take up nostalgia as a useful prism through which to interpret some of the main challenges confronting contemporary liquid-modern society. As an eminent example of this tendency is Zygmunt Bauman's book Retrotopia (2017), according to which we now live in an 'age of nostalgia'. This is, however, not any innocent form of nostalgia that is currently spreading. Rather, it is nostalgia in the incarnation of 'retrotopia' that now seems to roam across Western liberal democracies, demanding that we return to past forms and ways of life that promised more safety, certainty and predictability. Retrotopia - as the notion indicates - is not a forward-looking or future-oriented mentality, as is often - yet not necessarily - the case with utopia (from which it derives its name), but rather a backward-looking kind of nostalgic emotion that seeks solace 
from the pains of the present in the perceived and reconstructed cosiness and comforting predictability of the past. Bauman suggests that what we have witnessed with the rise of retrotopia amounts to nothing less than a U-turn of utopia, being once forward-directed and concerned with shaping the future, now instead it in its retrotopian guise looks backwards to find meaning and direction in what once was.

Retrotopia thus epitomizes the realization that has gripped growing parts of the social and political landscape that the hope of making the world a better place has been squeezed to the side by what Bauman regards as reactionary and/or regressive social forces. As Bauman observes on this U-turn of utopian hopes:

"[F]rom investing public hopes of improvement in the uncertain and ever-too-obviously un-trustworthy future, to re-reinvesting them in the vaguely remembered past, valued for its assumed stability and so trustworthiness. With such a U-turn happening, the future is transformed from the natural habitat of hopes and rightful expectations into the site of nightmares" (Bauman 2017: 6).

Retrotopia, at least in Bauman's rendition, thus inaugurates a contemporary dystopia of sorts - a dystopia that creates conflicts and chasms between people and groups. It sows distrust, breeds anger and anxiety and fundamentally rests on a divisive agenda. It is also a dystopia that according to Bauman - for all practical intents and purposes - is incapable of providing any genuine or lasting solutions to the very real problems confronted by liquid-modern society such as the consequences of globalization, individualization and cut-throat competition and consumerism. It signals a defensive, retreatist and inadequate strategy visà-vis the relentless and seemingly unstoppable processes that are currently shaping our today and tomorrow. From Boym's (2001) aforementioned book, the notion of 'restorative nostalgia' is thus useful for describing contemporary retrotopian tendencies because the purpose 
of retrotopia is to try to resuscitate the dead past in order to make it the guiding star for the living present.

Moreover, in Bauman's writings, there seems to be an intimate twoway connection or an almost inescapable loop between the development of 'the culture of fear' and the rise of retrotopia/nostalgia: fear breeds nostalgia and nostalgia breeds fear. While retrotopia/nostalgia is seen to function as a sort of bulwark against the feelings of fear, retrotopia itself also promotes its fair amount of fear of change and of everything that is new (as well as of 'strangers', 'outsiders', 'immigrants', deviants', etc.). Retrotopia/nostalgia thus serves as a tranquillizer in a world in which we are afraid of the present and the future (e.g. hoards of migrants, climate changes and new deadly viruses) and where we simultaneously have retreated from the activism that might provide us with actual solutions and instead turn towards political apathy. The defensive emotions of fear and retrotopia/ nostalgia thus seem to mutually reinforce each other so that the more fearful the population is, the more retrotopia/ nostalgia-prone it appears to become and vice versa. Such a circular or spiral-like development seems to suggest that it is difficult to break the strong chain of defensive emotions leading to defeatism and apathy but also to insensitivity and moral indifference (see, e.g., Bauman \& Donskis 2013).

There is undoubtedly something cooking and stirring in contemporary culture that justify defining our current times as 'nostalgic' and perhaps even as 'retrotopian'. There is plenty of evidence to support that people when confronted with the experience of troubles and crisis - and perhaps exacerbated especially by the current Covid-19 situation - are seeking comfort and relief in the ideas and practices of the past.

However, in his analysis of retrotopia, Bauman in many ways seems to be committing the same mistakes as many of those writing about the culture of fear' (including his own contribution). First of all, in Retroto- 
pia he almost exclusively associates nostalgia with something unfortunate and problematic, thus sidestepping evidence (e.g. from psychological and experimental research) that nostalgia can indeed serve good and positive purposes for individuals and society alike. Nostalgia, as several empirical studies within sociology and psychology have shown, is often a feeling that provides meaning and well-being to people (see, e.g., Wilson 2005/2014), and it may also strengthen a sense of community, belonging and optimism (see, e.g., Sedikides et al. 2015).

Second, Bauman primarily defines nostalgia (retrotopia) as a sort of regressive social force that threatens to tear society apart or which leads it in the wrong direction. But nostalgia is not in and by itself - any more than utopia, which is often hailed by Bauman as a harbinger of hope a regressive force, and perhaps retrotopia is neither. In fact, as Bauman once observed about utopia: Utopias may lead to a better life as much as they may mislead and turn away from what a better life would require to be done' (Bauman \& Tester 2001: 50).

The same probably also goes for nostalgia/ retrotopia: it may lead to a good life as well as mislead and take us to a dead-end. It is simply a double-edged sword like so many other social phenomena. Finally, in associating nostalgia/retrotopia mainly with a right-wing or populist agenda (and in this Bauman is far from alone but repeats the truism of many other social researchers writing on the topic of nostalgia), it appears as if nostalgia/retrotopia is only experienced and expressed, for example, by supporters of the Brexit movement, the Trump presidential campaign or by conservative governments in Visegrad countries, thus risking to reduce nostalgia/ retrotopia to a reactionary/ right-wing phenomenon - and thus missing its many other manifestations and forms of expression. By doing so, Bauman - together with others writing about the rise of nostalgia in contemporary times - comes close to committing the triple fallacies of limited representation, unnuanced nega- 
tivity as well as selective ascription. By transforming nostalgic sentiments mainly into (or by associating them primarily with) a retrotopian, regressive and right-wing populist tendency, the wider, potentially benevolent outcomes of nostalgia are thus missed and its positive possibilities are overlooked.

As mentioned, Bauman is not the only critical social theorist to have discovered the analytical potentials in nostalgia/ retrotopia for dissecting contemporary society. In his recent book The End of Illusions, Andreas Reckwitz (2021) has also argued that we are currently living through the 'end of illusions' (also the title of his book) and that we have entered a new phase of disillusionment and crisis. The utopian ideas and ideals associated with industrial modernity have come under attack, and they are increasingly replaced with comforting and alluring yet in many ways eerie images of a peaceful past before everything went wrong. Preferring the notion of 'late-modern' to Iiquid-modern' society, Reckwitz thus discusses how contemporary late-modern society is particularly prone to entertaining populist and nostalgic ideas, but he also regards the current state of disillusionment and crisis as a new opportunity. In all likelihood, with the recent writings of Bauman, Reckwitz and others, the road has now been paved for many coming critical analyses of the important role played by nostalgia/ retrotopia in liquidmodern society.

\section{Discussion and Conclusion}

This research essay has aspired to draw attention to the fact that in the wake of the establishment of 'the sociology of emotions' and perhaps particularly within certain sections of critical sociology or critical social theory, there has relatively recently developed an interest in using emotions (and specifically what has here been described as 'defensive moods') as analytical windows through which to glimpse wider social 
changes and cultural processes. Mostly, as has been suggested, the focus has been on emotions - such as fear and nostalgia/ retrotopia - that indicate and implicate a certain state of cultural crisis and social withdrawal. True, it has almost always been a sort of 'sociological disease' perhaps especially within critical branches of theorizing - to focus almost exclusively on the 'dark side' of social development, routinely neglecting all the positive aspects otherwise associated with social progress, technological improvement and human betterment. This was also the case with the early critical social theory (see, e.g., Mussell 2017).

In terms of emotions, this has therefore often resulted in studies of 'negative' emotional experiences such as stress, depression, suffering, anger, anxiety, injustice, humiliation, alienation, etc., with very little attention paid to positive emotions or to the potential positivity of emotions (even happiness is thus often defined as hollow or false and love as guided by self-interest or being manipulated by forces of 'commercialization' and a 'romanticideology').

This, however, is in fact not a new situation. Sociology has perhaps always been producing and providing critical diagnoses of the times. Back in the times of the writings of the 'founding fathers' of the discipline - Karl Marx, Max Weber, Émile Durkheim, Ferdinand Tönnies and Georg Simmel - there was also an extensive (however far from exclusive) focus on some of the prevailing negative moods and emotions of industrial/ capitalist society at the threshold from premodern to modern society. What was so characteristic of these classical sociologists was exactly their ability to balance a view of the positive as well as the negative aspects of the social changes they witnessed in the transition from premodern to modern society - and that there was always a darker side to what, at least to the untrained eye, appeared to be a desirable social development. 
For example, Marx wrote about alienation, Weber about the potentially devastating consequences of rationalization (such as loss of meaning and the Entzauberung der Welt), Durkheim analysed the causes of anomie, Tönnies discussed the dissolution and destruction of Gemeinschaft (community), and Simmel wrote about the rise of objective culture, cultural tragedy and the negative outcomes of the monetization of society. It seems as if there were plenty of reasons to raise the critical flag and to warn against some of the social currents and forces that shaped the emotional experiences of that time.

Today, at the threshold from a modern to a postmodern, late-modern, hyper-modern or liquid-modern era (the sociological epithets used to capture contemporary times are confusingly many), society, once again it seems, finds itself in a state of crisis with one crisis situation quickly succeeding, overlapping with or adding to the other: international terrorism crisis, financial crisis, climate crisis, and now the Covid-19 healthcare crisis - as well as many other threateninglocal and global scenarios. According to many critical social theories dealing with emotions, the outcome is a widespread sense of danger, doom and despair, resulting in defensive emotional responses such as fear and nostalgia/retrotopia. These are responses to a seemingly widespread feeling that society itself is under attack. As we have seen above, this literature on the 'culture of fear' and 'nostalgia/ retrotopia' has been booming in recent years, testifying not only to the poignancy and potency of the analyses provided but also to the popularity of these topics. It seems - perhaps particularly within sociological analysis - as if there is much more demand or resonance for the gloomy and sinister than for the optimistic and hopeful. Notwithstanding their importance, these analyses of the rise of defensive emotions, however, also beget a number of important questions.

Firstly, many of these theories of fear and nostalgia/ retrotopia seem to suggest that what we are currently witnessing is something new and 
almost unprecedented. Moreover, they seem to claim that fear and retrotopia/nostalgia are emotions on the rise. But was fear not also a prominent feature of social life prior to the rise of 'the culture of fear'? Looking through most parts of the $20^{\text {th }}$ century, the $19^{\text {th }}$ century, the $15^{\text {th }}$ century, the Middle Ages and so on, one is struck by how much fear then defined social life and how much of everyday life was centred around preparing for or dealing with the multiple sources of fear. Perhaps fear was even far more prevalent in previous times, because not only our relationships with other people - as we saw earlier - were fraught with risk and dangers, but so was also our relationship to nature (disasters) and to the frailty of the human body (illness). It is thus important - as was already hinted at earlier - to be clear on whether one writes about fear as a universal emotion (a so-called 'state') found in different times and cultures throughout human history but with the same physiologically and psychologically defining features, or if one is instead writing about fear as a relational and/ or cultural phenomenon (e.g. the 'culture of fear') that is not necessarily a stable and unchanging feature of human and social life.

Moreover, nostalgia was not an alien feeling to people living during the latter part of the $19^{\text {th }}$ century longing for the securities of premodern feudal society and dreading the coming of modern industrial society (although the understanding of what 'nostalgia' means and refers has changed quite considerably over time, see, e.g., Illbruck 2012; Pickering \& Keightley 2006). Nostalgia was, as mentioned, in fact originally an emotion that back in the $17^{\text {th }}$ century was defined as a disease among Swiss soldiers who longed for the hilly pastures of their home. Since then there have been many and more widespread nostalgia frenzies or retrotopia eruptions relating to collective feelings of loss of the past. So to suggest that fear and nostalgia/ retrotopia are today seemingly much more defining and prevalent features of social life than previously in human history requires more empirical documentation and historical 
qualification than what is often provided. In this research essay, it is neither questioned or doubted that fear and retrotopia/ nostalgia are indeed prominent and prevalent emotions in contemporary society, but is our current situation really as unprecedented and unparalleled as is often implied?

Second, the question also arises if many of these critical studies of defensive emotions such as fear and nostalgia/ retrotopia serve to create increased awareness of the current situation or if they in fact rather contribute to the alarmism and apocalyptic mood that has captured the public imagination? Knowing that the majority of sociology or social theory books is read primarily by academic 'insiders', the question still remains if these critical studies are relieving their readers (academic or non-academic) from their emotional distress, if they provide useful analytical tools and interpretative schemas with which to understand the situation or if they do in fact generate or reinforce the same sense of doom they seek to analyse, thus themselves becoming part of a self-fulfilling prophecy?

Finally, another - yet somehow related - question pertains to whether critical social theory in its analysis and diagnosis of the contemporary liquid-modern emotional landscape of fear and nostalgia/ retrotopia has succumbed to the same sense of defeatism and pessimism that it detects among 'ordinary people? It is quite seldom that these pieces of work contain any concrete answers to what could or should be done to counter 'the culture of fear' or the rise of retrotopia or that they provide solutions to the problem besides programmatical statements that we need to start listening to the 'voice of reason', that we should 'stand together' or that we should 'humanize society'. It all sounds beautiful, but almost always remains in the abstract. One could argue, as for instance Robert A. Stebbins (2009) has done, that we perhaps today need a 'positive sociology' rather than the negativistic view so prevalent among many sociologists - a positive stance that would 
allow us to see that most people most of the time - despite outside structural pressures, inequalities and injustices - in fact manage to live meaningful lives in which emotions such as fear and nostalgia/ retrotopia, for individuals and society alike, may sometimes even play a positive role (see, e.g., Shlapentokh 2006; Wilson 2004/2015). As everywhere else, in social analysis (as well as in critical social theory), the glass is not necessarily always half empty, it might in fact be half full.

With this research essay, it is my desideratum that the study of defensive emotions such as fear and nostalgia/ retrotopia (within 'the sociology of emotions', critical social theory and elsewhere) will continue in the time to come. However, it is also my hope that such studies first of all will begin to incorporate more empirical substantiation for the claims that fear and nostalgia/ retrotopia are indeed on the rapid rise in contemporary society, and secondly that a less defeatist, less negative, less normative (and thus less predictable) and more positive approach may start to develop.

Acknowledgements

The author wants to thank the two anonymous reviewers of this review essay for useful comments and insightful ideas on an earlier draft of the text.

\section{References}

Ahmed, S. (2004). The Cultural Politics of Emotions. Edinburgh: Edinburgh University Press.

Bader, Ch.D., Baker, J ., Day, E., \& Gordon, A. (2020). Fear Itself: The Causes and Consequences of Fear in America. New York: New York University Press. 
Bauman, Z. (1996). The Moth Seeks Out the Lamp. New Statesman 9 (427), 21-23.

Bauman, Z. (1997). Postmodernity and Its Discontents. Cambridge: Polity Press.

Bauman, Z. (1999). In Search of Politics. Cambridge: Polity Press.

Bauman, Z. (2006). Liquid Fear. Cambridge: Polity Press.

Bauman, Z. (2017). Retrotopia. Cambridge: Polity Press.

Bauman, Z., \& Bordoni, C. (2014). State of Crisis. Cambridge: Polity Press.

Bauman, Z., \& Donskis, L. (2013). Moral Blindness - The Loss of Sensitivity in Liquid Modernity. Cambridge: Polity Press.

Bauman, Z., \& Tester, K. (2001). Conversations with Zygmunt Bauman. Cambridge: Polity Press.

Bailey, J . (1988). Pessimism. London: Routledge.

Beck, U. (1992). The Risk Society. London: Sage Publications.

Becker, H. (1963). Outsiders: Studies in the Sociology of Deviance. Glencoe: Free Press.

Bericat, E. (2016). The Sociology of Emotions: Four Decades of Progress. Current Sociology 64 (3), 491-513.

Bourke, J . (2005). Fear: A Cultural History. London: Virago.

Boym, S. (2001). The Future of Nostalgia. New York: Basic Books.

Bude, H. (2014). Society of Fear. Cambridge: Polity Press.

Bude, H. (2018). The Mood of the World. Cambridge: Polity Press.

Clark, C. (1997). Misery and Company: Sympathy in Everyday Life.

Chicago: University of Chicago Press.

Collins, R. (2004). Interaction Ritual Chains. Princeton: Princeton University Press.

Cohen, S. (1972). Folk Devils and Moral Panics: The Creation of the Mods and Rockers. London: MacGibbon and Kee Ltd.

Darwin, Ch. (1872/ 1999). The Expression of the Emotions in Man and Animals. New York: Harper-Collins. 
Davis, F. (1979). Yearning for Yesterday: A Sociology of Nostalgia. New York: Free Press.

Edgework - The Sociology of Risk-Taking . (2004). (Ed.) Lyng, S. London: Routledge.

Emotions, Everyday Life and Sociology. (2019). (Ed.) J acobsen, M.H. London: Routledge.

Emotions in Culture and Everyday Life. (2022). (Ed.) J acobsen, M. London: Routledge.

Entertaining Fear: Rhetoric and the Political Economy of Control. (2010). (Eds.) Chaput, C., Braun, M., \& Brown, D. New York: Peter Lang.

Freud, S. (1930/2002). Civilization and Its Discontents. London: Penguin Books.

Furedi, F. (1997). The Culture of Fear. London: Cassell.

Furedi, F. (2005). Politics of Fear: Beyond Left and Right. London: Continuum.

Furedi, F. (2018). How Fear Works: The Culture of Fear in the $21^{\text {st }}$ Century. London: Bloomsbury.

Gardner, D. (2008). Risk: The Science and the Politics of Fear. New York: Virgin Publishing.

Gardner, D. (2009). The Science of Fear: How the Culture of Fear Manipulates Your Brain. NewYork: Plume Books.

Giddens, A. (1979). Central Problems in Social Theory. London: Macmillan.

Giddens, A. (1990). The Consequences of Modernity. Cambridge: Polity Press.

Glassner, B. (1999). The Culture of Fear: Why Americans are Afraid of the Wrong Things. New York: Basic Books.

Goode, E., \& Ben-Yehuda, N. (1994). Moral Panics: The Social Construction of Deviance. New York: Wiley/ Blackwell. 
Hochschild, A.R. (1975). The Sociology of Feeling and Emotion: Selected Possibilities. [In:] Another Voice: Feminist Perspectives on Social Life and Social Science. (Eds.) Millman, M. \& Kanter, R.M. (280-307). New York: Anchor Books.

Hochschild, A.R. (1983). The Managed Heart: Commercialization of Human Feeling. Berkeley, CA: University of California Press.

Hochschild, A.R. (1998). The Sociology of Emotions as a Way of Seeing. [In:] Emotions in Social Life. (Eds.) Bendelow, G. \& Williams, S.J . (3-15). London: Routledge.

Hofer, J . (1688/ 1934). Medical Dissertation on Nostalgia by J ohannes Hofer, 1688. Bulletin of the History of Medicine 2, 376-391.

Illbruck, H. (2012). Nostalgia: Origins and Ends of an Unenlightened Disease. Boston: NorthWestern University Press.

Intimations of Nostalgia: Multidisciplinary Explorations of an Enduring Emotion. (2021). (Ed.) J acobsen, M.H. Bristol: Bristol University Press.

Jacobsen, M.H. (2020b). Liquid-Modern Emotions - Exploring Zygmunt Bauman's Contribution to the Sociology of Emotions. Emotions and Society 1(1), 99-116.

Koczanowicz, L. (2020). Anxiety and Lucidity: Reflections of Culture in Times of Unrest. London: Routledge.

Martin, B. (1981). A Sociology of Contemporary Cultural Change. New York: St. Martin's Press.

Massumi, B. (1993). Everywhere You Want to Be: Introduction to Fear. [In:] The Politics of Everyday Fear. (Ed.) Massumi, B. (3-38) Minneapolis: University of Minnesota Press.

Meštrović, S.G. (1997). Postemotional Society. London: Sage Publications.

Mussell, S. (2017). Critical Theory and Feeling: The Affective Politics of the Early Frankfurt School. Manchester: Manchester University Press. 
Nostalgia Now - Cross-Disciplinary Perspectives on the Past in the Present. (2020). (Ed.) J acobsen, M.H. London: Routledge.

Pickering, M., \&Keightley, E. (2006). The Modalities of Nostalgia. Current Sociology 54 (6), 919-941.

Reckwitz, A. (2021). The End of Illusions: Politics, Economy and Culture in the Late-Modern Age. Cambridge: Polity Press.

Research Agendas in the Sociology of Emotions. (1990). (Ed.) Kemper, Th.D. New York: State University of New York Press.

Robin, C. (2004). Fear: The History of a Political Idea. New York: Oxford University Press.

Roser, M., Ortiz-Ospina, E., Ritchie, H. (2019). Life Expectancy. Our World in Data, https:/ / ourworldindata.org/life-expectancy.

Schultz, N.L. (1998). Fear Itself: Enemies Real and Imagined in American Culture. Purdue: Purdue University Press.

Sedikides, C., et al. (2015). To Nostalgize: Mixing Memory with Affect and Desire. Advances in Experimental Social Psychology 59, 189258.

Serres, M. (2013). Times of Crisis. New York: Bloomsbury.

Shlapentokh, V. (2006). Fear in Contemporary Society: Its Negative and Positive Effects. London: Palgrave/Macmillan.

Siegel, M. (2006). False Alarm: The Truth about the Epidemic of Fear. New York: Wiley.

Skoll, G.R. (2010). Social Theory of Fear - Terror, Torture and Death in a Post-Capitalist World. London: Palgrave/ Macmillan.

Skoll, G.R. (2016). Globalization of American Fear Culture - The Empire in the Twenty-First Century. New York: Springer.

Slovic, P. (2010). The Feeling of Risk: New Perspectives on Risk Perception. London: Routledge.

Stebbins, R.A. (2009). Personal Decisions in the Public Square: Beyond Problem Solving into a Positive Sociology. New Brunswick, NJ : Transaction Publishers. 
Thompson, K. (1998). Moral Panics. London: Routledge.

Tudor, A. (2003). A (Macro) Sociology of Fear. Sociological Review 51 (2), 238-256.

United States Senate (1933). The 37th Presidential Inauguration: Franklin D. Roosevelt, March 4, 1933'. Washington, DC: Unites States Senate. https:// www.inaugural.senate.gov/37th-inauguralceremonies/.

Wilkinson, I. (2001). Anxiety in a Risk Society. London: Routledge.

Wilson, J.L. (2005/2014). Nostalgia: Sanctuary of Meaning. Minneapolis: University of Minnesota Publishing. 